\title{
Redo in aortic homograft replacement: Transcatheter aortic valve as a valid alternative to surgical replacement
}

\author{
Luca Dainese, MD, Melissa Fusari, MD, Piero Trabattoni, MD, and Paolo Biglioli, MD, Milan, Italy
}

Reintervention in patients who have undergone an aortic homograft valve replacement remains a technical challenge. We report the case of a patient with multiple aortic valve replacements having an aortic homograft with severe calcific stenosis who successfully underwent transcatheter aortic valve insertion (TAVI).

\section{CLINICAL SUMMARY}

A 48-year-old woman was referred to our hospital with symptoms of ingravescent severe dyspnea. Fifteen years earlier, she had undergone placement of a $21-\mathrm{mm}$ aortic valve Bravo 400 stentless xenograft (Cryolife International, Atlanta, Ga). Four years later, she underwent a valve replacement with a 21-mm mechanical prosthesis (Carbomedics, Austin, Tex) for valve degeneration, and subsequently, she received a homograft for aortic valve endocarditis.

The echocardiographic control, performed during the last 15 years, showed progressive calcific valve degeneration

From the Department of Cardiovascular Surgery, University of Milan, Centro Cardiologico Monzino IRCCS, Milan, Italy

Disclosures: None.

Received for publication June 29, 2009; accepted for publication July 5, 2009; available ahead of print Aug 19, 2009

Address for reprints: Luca Dainese, MD, Department of Cardiovascular Surgery, University of Milan, Centro Cardiologico Monzino IRCCS, Via Parea 4, 20138 Milan, Italy (E-mail: luca.dainese@ccfm.it).

J Thorac Cardiovasc Surg 2010;139:1656-7

$0022-5223 / \$ 36.00$

Copyright $\Subset 2010$ Published by Elsevier Inc. on behalf of The American Association

for Thoracic Surgery

doi:10.1016/j.jtcvs.2009.07.006 with a peak transvascular pressure gradient of $41 \mathrm{~mm} \mathrm{Hg}$ and aortic valve area of $0.5 \mathrm{~cm}^{2}$. Preoperative computed tomographic angiographic analysis showed diffuse aortic root calcifications (Figure 1), and the patient presented with symptoms of severe aortic stenosis. She also presented with multiple comorbidities and a logistic EuroSCORE of 11.85\%.

The procedure was performed after achievement of general anesthesia through a transapical approach. A 23-mm Edwards SAPIEN Transcatheter Heart Valve (Edwards Lifesciences, Irvine, Calif) was used.

A 5-cm-long thoracotomy in the sixth left intercostal space was performed. After the insertion of myocardial pacing electrodes and the dissection of pericardial adherence, the left ventricle was exposed, and its apex was punctured.

An Amplatz Extra Stiff 0.35-inch wire (Cook Medical, Bloomington, Ind) was inserted through the stenotic aortic valve homograft. A $14 \mathrm{~F}$ introducer sheath was inserted over the guidewire, with the tip of the sheath positioned in the middle of the left ventricle.

Fluoroscopy was used to position the inflow part of the homograft valve just below the annulus (Figure 2).

During rapid cardiac pacing (200 beats/min), the aortic valve homograft was dilated.

The 23-mm Edwards SAPIEN Transcatheter Heart Valve was implanted during rapid pacing (200 beats/min) within the degenerated aortic homograft (Figure 3).

After deflation of the stent valve balloon, the patient recovered rapidly with normal hemodynamic parameters. Both the intraoperative transesophageal echocardiographic analysis and an aortogram showed a functioning valve

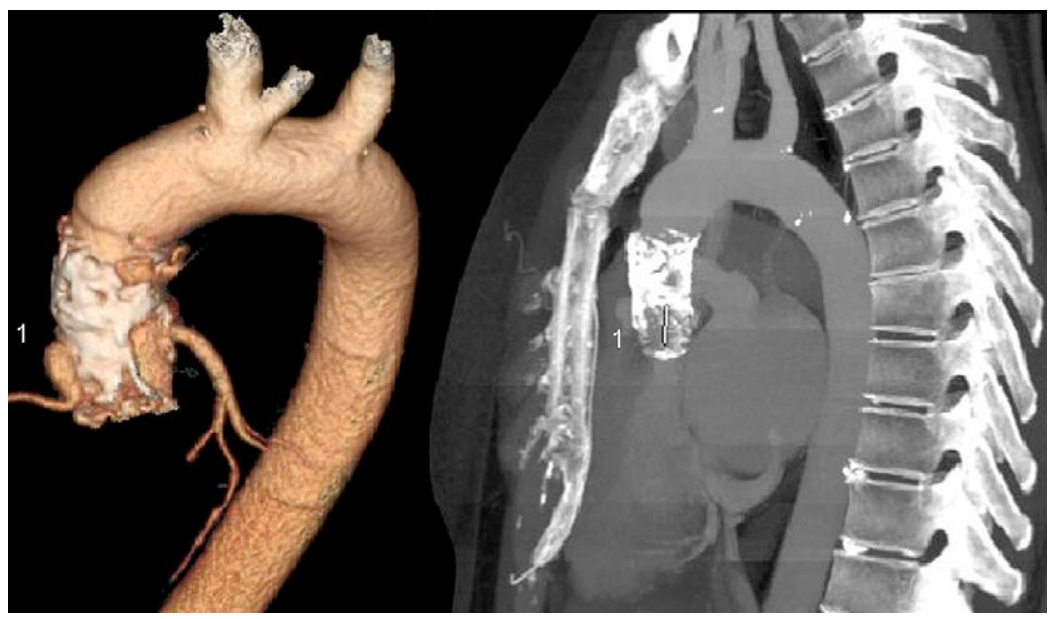

FIGURE 1. Thoracic computed tomographic angiogram showing the extremely calcified aortic root (1). 


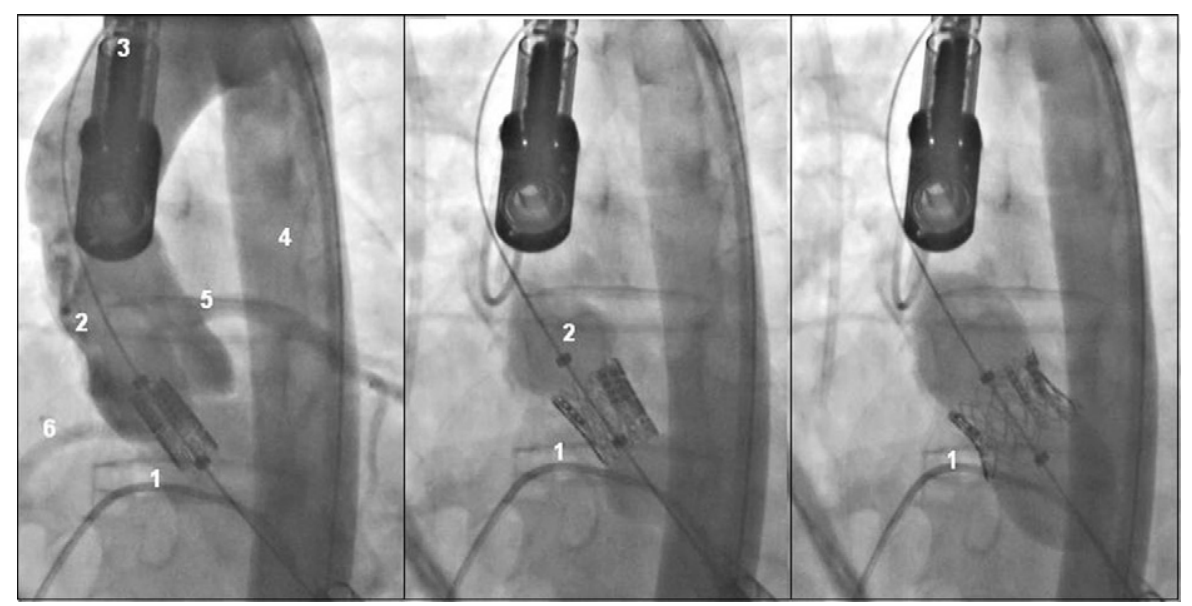

FIGURE 2. Angiographic sequence of transcatheter valve deployment. The valve is opened during rapid right ventricular pacing, decreasing the risk of device migration. 1 , Transcatheter valve; 2 , aortic root; 3 , transesophageal echocardiography; 4 , descending aorta; 5 , left main Coronary artery; 6 , right coronary artery.

without evidence of regurgitation or paravalvular leak. The transvalvular gradient was $18 \mathrm{~mm} \mathrm{Hg}$ in the immediate postoperative control period.

The patient was discharged from the hospital 8 days after the procedure. Both clinical follow-up and transthoracic echocardiographic control showed good valve functioning without paravalvular leaks or insufficiency and a transvalvular gradient of $23 \mathrm{~mm} \mathrm{Hg} 6$ months after the TAVI procedure.

\section{DISCUSSION}

Aortic valve replacement in patients who have previously undergone aortic valve replacement with a homograft remains a technical challenge, particularly in extremely calcified aortic roots. Perioperative mortality for aortic homograft redo surgery is reported to be between $3 \%$ and $8 \%{ }^{1,2}$

In the reported case the aortic root was submitted to 3 previous surgical interventions. As we know, calcification can affect the cusps, the homograft annulus, and the homograft wall. Calcification can be so extensive that the aortic root becomes completely rigid.

The cardiovascular team was conscious that the aortic calcified root should be dissected with a retrograde approach, particularly between the ascending aorta and the aortic arch. As confirmed by means of computed tomographic angiographic scanning, the aortic root appears to be a very calcific and friable structure.

As we know, the transfemoral approach with forces applied to the aortic arch by retroflex devices during valve advancing can result in a very high possibility of thoracic aortic dissection. Thus we choose a transapical approach, permitting us to avoid sternal re-entry and the surgical difficulties represented by the extremely calcified aortic root.

Also, it is known that native valve predilatation with a balloon can cause possible leaflet calcium debris. As a matter of fact, calcification was normally found at the commissural level and at the cusp's free margins, with spots of calcification that are widely detected in the belly of the leaflets particularly affecting the base. ${ }^{3}$

Because the aortic homograft was inserted with a miniroot technique, we decided to slowly open the balloon valve deployment at 2 times, thus permitting gentle valve displacement and avoiding the valve switching from the aorta to the left ventricle.

In this particular case, with the patient undergoing 3 sternal openings and 4 interventions (in the heart or aortic root), the TAVI procedure could represent a very interesting option compared with the traditional surgical approach. Patients with multiple valve redo operations could benefit from this technique that, when performed by a skilful cardiovascular team, can represent a safe and successful alternative.

\section{References}

1. Kumar P, Athanasiou T, Ali A, Nair S, Oz BS, DeSouza A, et al. Redo aortic valve replacement: does a previous homograft influence the operative outcome? J Heart Valve Dis. 2004;13:904-13.

2. Joudinaud TM, Baron F, Raffoul R, Pagis B, Vergnat M, Parisot C, et al. Redo aortic root surgery for failure of an aortic homograft is a major technical challenge. Eur J Cardiothorac Surg. 2008:33:989-94.

3. Melina G, Horkaew P, Amrani M, Rubens MB, Yacoub MH, Yang GZ. Threedimensional in vivo characterization of calcification in native valves and in Freestyle versus homograft aortic valves. J Thorac Cardiovasc Surg. 2005;130:41-7. 